\title{
Frameless
}

Volume 1 | Issue 1

Article 22

November 2019

\section{Adjusting the Margins: Harnessing the Foundations of American Sign Language for VR}

Luane Davis Haggerty

National Technical Institute for the Deaf, LRDNPA@rit.edu

Follow this and additional works at: https://scholarworks.rit.edu/frameless

\section{Recommended Citation}

Haggerty, Luane Davis (2019) "Adjusting the Margins: Harnessing the Foundations of American Sign Language for VR," Frameless: Vol. 1: Iss. 1, Article 22.

DOI: 10.14448/Frameless.01.009

Available at: https://scholarworks.rit.edu/frameless/vol1/iss1/22

This Article is brought to you for free and open access by RIT Scholar Works. It has been accepted for inclusion in Frameless by an authorized editor of RIT Scholar Works. For more information, please contact ritscholarworks@rit.edu. 


\title{
FRAMEIESS
}

\section{Adjusting the Margins: Harnessing the Foundations of American Sign Language for VR}

\author{
Luane Davis Haggerty \\ Department of Cultural and Creative Studies \\ National Technical Institute for the Deaf
}

Abstract: Del-Sign is a physical approach to acting that uses elements of Francois Delsarte mime techniques with the foundations of American Sign Language. This acting and presentational technique uses cross-cultural physical communication as a way to deepen an actors' performance, support a presenter's lecture, or can be used as a format from which to create animations that communicate with or without verbal language. It is a historical fact that Deaf actors using the foundations of Sign Language influenced the movie industry (Higgins). In silent movie infancy Deaf performers were brought in as consultants to ensure that the gestures, relational positions, facial expression, camera angles and body language of the actors could have the strongest impact and the clearest meaning (Albert Ballin). At that time the standard acting technique was a codified movement study begun and refined by Francious Deslarte (1870-1890s Paris, 1880-1915 Steele MacKaye New York). By blending these two structures we find that an outline is gained for creating movement, posture and gesture (MPG) that easily communicates meaning. The applications of this performance technique are many and varied. From the obvious acting for stage application to lawyers, teachers, priests or other presenters. Del-Sign can now bridge into adding technology to the mix allowing for this approach to be used when creating characters and movement for VR, AR or MR. 
Vol. 1, No. 1 - 2019

Frameless

\section{INTRODUCTION}

We have found that creativity can't be outsourced, it is not an innate talent that you either have or do not have. Creativity as a way of thinking can be encouraged, refined and skills can be developed to enhance creative approaches to work. In a global economy This cross-cultural approach encourages collaborative work and moves concepts from the abstract to the concrete. This 20 minute talk for the Framelss Conference can explore the storytelling potential of how Del-SIgn can influence VR and how VR practices can employ this blended storytelling and performance technique. It can be used to enhance and reinforce the development of plotlines and immersive narrative architectures. By discussing the history ASL has and Deaf cultural perspectives share with the movie industry this talk can also touch on cinematic explorations of storytelling, theatrical and performative practice in XR. This presentation will include both video and live performance examples of Del-Sign.

\section{INCORPORATING ACTORS WITH DISABILITIES}

Incorporating actors with disabilities leads to a perceptual shift for those of us who tend to think of "difference" as a problem to work around and change that thinking into using actors, designers and backstage workers who navigate the world differently as an asset. At first blush CD, Game design, AR, VR might think of using Sign as a way of working new systems - kind of a "Minority Report”. But Deaf cultural perceptions ways of presenting "story" and physical communication expertise have much more to add to the development of the technology.

\section{NON-TRADITIONAL CASTING}

We have long heard the idea that colorblind casting is "innovative." I challenge that idea and would prefer to think in terms of nontraditional casting. First and foremost is the story we are trying to tell in a theatrical living moment. Trying to combine politics and art often ends up like Dr. Dolittle's "Push-me/Pull-you". If the art and the story remain relevant then the communication that happens in live theater between stage and audience will be unbroken. For a director, finding that relevance when you want to use the acting skills of an actor with an unexpected image is hard. The director knows that the impression of a character is set in the first few minutes. A casting mistake with a visually sophisticated millennial audience can disrupt the entire storyline. If you ignore the audience's perspective you risk causing an unnecessary challenge to the audience's suspension of disbelief. If a change is desired and Othello is not black or Hamlet is not a boy some directorial guidance is needed so that audience stays with the story and does get stuck on the mental confusion created by an unexpected appearance.

How can you begin to incorporate actors with disabilities? Do you want to? Examine why you want to and which disabilities. Clearly you will want the most highly skilled actors you can find regardless of physical challenges. If a fine actor who has mobility challenges comes to your audition for Richard for Henry IV part 3 - he might be the best 
choice (Richard has a physical challenge). Even when the text suggests no disability, there are other reasons to open you stage to possibilities. Perhaps you have someone in your regular cohort of company members who has been recently injured, had an illness or is not the perfectly fit person you are used to dealing with. None of us are permanently able bodied - there is no real "them" and "us". Set designs (and theater rentals) with elevators, lifts and ramps help out the kid on crutches, the Mom with a baby carriage and the older person with a cane as well as it serves the infrequent audience member in a wheelchair.

\section{DEL-SIGN AS A TECHNIQUE FOR EXPANDING CASTING HORIZONS}

I have been developing a theatrical fusion of cultures using François Delsarte codified movement and American Sign Language. Del-Sign is an experimental technique that combines the foundations of Delsarte's concepts with the structure of American Sign Language to create an external (physical) approach to acting. It is not intended to replace the techniques an individual actor already has in place; it is intended as a way to round-out or complete the presentational vocabulary of the actor or speaker so that they can approach the work in a more informed way.

\section{SO IS THIS EXPERIMENTAL THEATER?}

When people say "experimental theater" they often seem to think the word experimental means new or non-realistic or weird. But in fact, what makes it experimental is exactly the same thing that makes experimental physics experimental - that it proceeds by means of experiments, by people trying things out to see what works, rather than by holding to a belief in a system, or by dedicating themselves to one or another theory or aesthetic. To that end yes, it is experimental.

Del-Sign combines Francois Delsarte codified movement techniques and American Sign Language. Often when I direct in this style I use two actors for each role. One represents the body of the character (spoken in English and played much as you would expect) and the other represents the emotions or spirit of the character (In the RCP production of Midsummer which drew hundreds of audience members over the three week run, winning CITY Newspaper's “Best Local theater Production" of 2014, all of the fairy characters were Deaf and used Sign. All of the humans were assigned a "guardian" fairy this deepened the concept of a human/fairyland divide and created a fairyland culture and language separate from the humans. Coincidentally it also provides the practical benefit of being accessible to the Deaf audience members every night).

\section{WHO WAS DELSARTE?}

Francois Delsarte was born in 1811 and was an orphan by the age of nine. He made his way 
in the world by rag picking. Pere Bambini took the poor little boy under his wing and discovered Francois' natural musical talents. Bambini enrolled the boy in the Conservatory for Music in Paris. Delsarte had a hard time at the Conservatory as he felt that his instructors were unable to teach him a truthful way to present his art. At that time students were expected to imitate the master without analyzing the technical components of their style.

Regardless of this problem in training, Delsarte became a regular principle performer with the Lyric Opera in Paris. It was there that tragedy struck. Due to poor vocal training Delsarte lost his voice. Fearful of losing his job (and financial security) he continued to perform. Opera was not the sedate performance style we know today. In Delsarte's day it was noisy and busy with the audience watching itself as much as they watched the stage. Delsarte's physical interpretation of his roles was so compelling that no one noticed he wasn't singing for quite some time.

Although his abilities created a sensation, Delsarte chose to continue to study what he called, The Natural Laws of Expression. He spent time watching people in all types of situations, children at play, wives waiting for word of their husbands after a mine collapse, deathbed watches, etc. All this to see how people naturally expressed themselves. It is speculated that he even spent time in the French Deaf Community in Paris at that time. He went even further by studying physiology and taking part in autopsies. He found that there is a common physical form of communication regardless of language or cultural background.

He broke his findings into the Law of Trinity.
"The unity of three things, each of which is essential to the other two, each co-existing in time, co-penetrating in space, a co-operative in motion. Many religions have the concept of the Trinity, most notably the Hindu with its Brahma, Siva and Vishnu. So it is with representing life. In the case of the performance it is essential TO KNOW, TO DO AND TO BE."

Delsarte as quoted in Ted Shawn's EVERY LITTLE MOVEMENT (graphic on right appears in "Every Little Movement" graphic available through Lincoln Center Performing Arts Library)

As with anything popular, Delsarte's technique was turned to kitch soon after his death in 1871 . He was virtually a National hero to the French. Several of his students came to America and began to teach the technique here. Steele Macaye and Mrs. Hovey were the only true teachers of the original concept. Most of my knowledge of Delsarte's technique comes from their writings on the subject. Delsarte himself, never wrote anything down for as we know from a personal letter written to his daughter in 1868: "I do believe that my concept of the Laws of Nature are ever developing. I am therefore loath to write them down thereby freezing the concept in time and in turn creating an untruth."

By 1880 Delsarte's interest in the truth was drowned in a flood of pseudo-Delsarte teachers who took the basic tenants, the basic exercises and turned them into a "gymnastic". As the technique became more and more distilled it faced more and more derision. Not surprisingly for our purposes Delsarte's technique was given a fresh breath of life when Albert Ballin (a notable Deaf author) used his knowledge of Delsarte's technique to 
teach two Deaf girls performing in the Silent movies of the time a performance piece. The performance was heralded as "truthful", "wondrous", but the fact that the performers were Deaf somehow discredited their use of Delsarte's technique and it was considered a fluke (this story is related in THE DEAF MUTE HOWLS by Albert Ballin)

\section{AMERICAN SIGN LANGUAGE (ASL) IN THEATRE}

ASL and Deaf performers have a long and detailed history of performance and storytelling. Many of the greatest contributions have been made by theatre companies which focus on Deaf performers and audiences namely; The National Theater for the Deaf, among many others. I would encourage you to go see the work of other companies which use American Sign Language in performance: The New York Deaf Theater and Deaf West to name a few.

For our purposes ASL has many applications. ASL grammar: the proper facial expression is tantamount to proper punctuation. Eye contact and focus is not only used for human contact and communication but also as a way of establishing character and reference points. ASL structure: requires the signer to have a very visual frame of reference. Rather than focusing on beauty of sounds ASL focuses on beauty of images. There are specific constructions which use a term "cinematic" meaning the idea of describing with long shots and close shots similar to how a movie will tell a visual story. As one of my mentors George Garcia often points out the world is becoming more visually based soon the division between "hearing" and Deaf will melt in a common goal toward a visual world. Take for example the technique often used in Story Sign of role shifting. That is, when a person tells a story $\mathrm{s} / \mathrm{he}$ take on the characters rather than going with the construct of "he said" "she said". This is a common tool used on stage by actors which have no knowledge of ASL. As obvious as it may seem ASL is crucial to the development of stage performance in that the "voice" of the language or emotive tone, is facial expression, body language and gesture. ASL combines these elements in a highly refined way to physically produce communication of higher concepts. These are the same tools that actors need to refine in order to make the emotional subtext of the character shine through.

Although Delsarte did not know Sign, his point of view is in direct synch:

"Gesture is the direct agent of the heart, the persuasive agent. The language of the hand is a universal language; some communication can be made with descriptive pantomime, but many gestures are universal "words". We all recognize the hand movements which say "come here", "hello", "good-bye". I am sure the list is virtually limitless. Gesture has been given to man to reveal what speech is powerless to express. If we desire that a thing shall always be remembered, we must not say it in speech; we must let it be divined in gesture. Gestures relate us to other beings, expressing our emotions, from the highest to the lowest." 
Vol. 1, No. 1 - 2019

Frameless

\section{WHERE ELSE HAS THIS BEEN DONE?}

Deaf West's Broadway production of "Big River" used elements of Del-Sign most particularly with the role of Papp. This could be the result of a "common consciousness" within the creative world but given that a director's vision is often brought to life in combination with the artistic staff and colored by the actor's interpretation - some of the "coloring" was no doubt contributed by six of the original cast members who had worked in the Del-Sign style previous to work with Deaf West. Although three of the actors were in the chorus and would not have had any influence, the other three; Guthrie Nutter (Twelfth Night) Michelle Banks (Noises Off) Iosif Schniederman (Noises Off, Tempest) all had principle roles and Iosif was originally cast as Papp. He was injured in the opening performance by a set piece and replaced early in the run of the show. However, he has since described how his suggestion in rehearsal to consider doubling the role in Del-Sign style was accepted. (see also New York Times, Sunday August 3, 2003 Art Section, letter to the Editor "Blending Cultures")

\section{HOW TO USE DEL-SIGN IN YOUR OWN WORK}

Some of the activities or exercises that this presentation will introduce you to were developed in order to create a physical approach to supporting the meaning of the test. A beautiful voice using beautiful language is an attraction but stage is visual. The audience needs to see and hear the text in order to best understand what they are hearing and apply it to what they know of life.

Is this innovative? Yes, but it isn't actually "NEW." It's the way this ideas blend that creates the innovation. Delsarte's (陽), fied movement, foundations of Sign language surprisingly are in harmony with some of the earliest Chinese legends from $\mathrm{a}_{(\text {陰}),}$, 3000 BCE. This fusion of techniques and theories explains the nature of innovation as energy, that flows in complement with each other to achieve success.

\section{DELSARTE FOCUSED ON AN OVERALL APPROACH TO HIS WORK - TO KNOW, TO DO AND TO BE ${ }^{1}$}

\section{To Know}

The concept of Yin and Yang: Yang discloses itself as "active, firm, light, initiative, contractive, immaterial, affirming, turned on, sustaining, and positive" while Yin as "passive, dark, material, yielding, soft expansive, nourishing, pliable, turned off, and negative" (Secter, 1993, p, 18). A dualistic universe, however, consists of varying degrees of difference. As yang energy is likened to days and yin energy to nights in the nature's order. Within each, there is an element of the other-in bright daylight, there is shadow or darkness,

\footnotetext{
${ }^{1}$ Information on the I'Ching thanks to Carolyn Yu of the Antioch University Ph.D. Program.
} 
within the night shines the brightness of the moon and stars.

This parallels the Del-Sign concept of "partner work on stage." In general, one actor portrays the body/human element of the character (Yang) and the other actor portrays the spirit/subconscious/emotional life of the character (Yin). Exercises to enhance this duality in a concrete reality include: eye contact and breathing: the entire group inhales and exhales together in an exaggerated manner three times. Then one person who makes eye contact and exhales starts the breath, the person with whom they made eye contact inhales changes focus and exhales. This continues around the circle. As the cast becomes more familiar with the activity and the show, the breath can suggest a gesture or a mimed object that is related to the show in some way. For example: blowing bubbles, exhaling a cigarette, sneezing, blowing a kiss, or throwing a basketball. As the actors become more advanced, the breath incorporates lines from the show. This activity can be used with scene partners, as well, outside of a general warm-up. It is of interest to reiterate how this activity combines aspects of both Delsarte Systems and American Sign Language. The rhythmic breath and control are similar to those mentioned by Shawn (1954) while the structure of the exercise-standing in a circle and emphasis on eye contact is appropriate to deaf cultural habits (Gannon, 1989).

\section{To Do}

The actors need to agree on the intensions, motivations and goals of their shared character. If the spirit cannot physically communicate with their human they can use the four elements (or Shakespearian Humours) earth, air, fire, water. For example: The wind blowing drops dust in your eyes and you stop, or the weather changes and sends you in a new direction.

This parallels the Del-Sign activity of "center of gravity characters." Although there are an infinite number of character types to be portrayed the essential element of them can be built upon where the character holds his center of gravity. Delsarte began with three character types: Intellectual- center of gravity high, detailed gesture and sharp movement. Emotional- center of gravity in the chest (expanded or concave) gestures are fluid and smooth, movement is graceful.. Physical - the center of gravity is in the hips, gestures are punches or slices in the air, movement is animalistic and sensual.

Further, in "Role Playing," each member of the group borrows another actor's physical expression or movement and then shifts back to themself. In an intermediate level, one actor copies someone else's movements in the production they are currently working on. At more advanced levels, they illustrate only those characters that are American Delsarte examples of character types. The three basic types outlined by Delsarte are, in brief: 1) intellectual types who have their center of gravity high, their sign or gesture choices are detailed, their movements are sharp and staccato. 2) Emotional types have their center of gravity in the chest area, their sign or gesture choices are fluid, smooth and often expressed at chest level. 3) Physical types have their center of gravity low and into the hips. Their sign or gesture choices are fists or open hands and are often expressed in the lower abdomen area. The technique of role shifting is common in American Sign Language and is discussed at some length 
in the Registry of Interpreters for the Deaf (RID) Newsletter VIEWS (June 2001). There are also full body charts as shown in Every Little Movement (Shawn, 1954) in this way personality is physically explored without judgment allowing practice of cross-cultural understanding and communication.

\section{To Be}

This is the hardest element to explain it is what we tend to call stage presence. It is the energy and intensity an actor brings to stage. Ancient Chinese I-Ching (Book of Changes), yin and yang philosophy and modern quantum theory share a common perspective-energy. Quantum theory describes atomic movements in terms of transcendent matter in an energy field. The I-Ching explains events and actions as the consequence of energy polarity with variations caused by energy synchronicity resulting from opposition and complementarity. DelSign links real life experiences with analysis of character and nature.

\section{Links to Media:}

"Crazy" by Dangerous Signs https://vimeo.com/154741895

"His Mother was a Votress," 2015

https://www.youtube.com/ watch? $\mathrm{v}=2 \mathrm{sP} 8 \mathrm{qGBoQRw} \& \mathrm{t}=1 \mathrm{~s}$ 